\title{
Smart Nanocontainers: Preparation, Loading/Release Processes and Applications
}

\author{
Tuan Anh Nguyen ${ }^{1 *}$, Aymen Amine Assadi ${ }^{2}$ \\ ${ }^{1}$ Institute for Tropical Technology, Vietnam Academy of Science and Technology, Hanoi, Vietnam. \\ ${ }^{2}$ Ecole Nationale Supérieure de Chimie de Rennes 11, Allee de Beaulieu- CS 50837 - 35708 Rennes Cedex 7, France.
}

Received July 09, 2018; Accepted July 18, 2018; Published July 20,2018

Copy right: (C) 2018 Nguyen T A, et al

\begin{abstract}
This article presents a review on smart nanocontainers, dealing with various aspects, such as their definition, classification, preparative methods, loading/release processes and recent applications. It covers advanced applications in the areas of smart coatings, drug delivery, molecular biology, environment, anticorrosion, agri-food, gas storage.
\end{abstract}

Keywords: Nanomaterials; Nanocontainer;Nanocapsules;Nanoshell;Nanocarriers; Nanotube;Nanolayers;Drugdelivery; Corrosion inhibitors; Catalysts; Argi-food; Gas storage.

\section{Introduction}

\section{Definition}

Nanocontainer is a nanosized volume (in at least one dimension), which contained the active substances in its interior (hollow structure) or in inner cavities (porous structure). The smart nanocontainers are typically related with the smart releasing property for their embedded active substances. These smart releases could be obtained by using the smart coatings as their outer nanoshells. In this regard, the active agents could be released from nanocontainers by external or internal stimuli, which referred to the chemical/physical/biochemical changes within or surrounding of the nanocontainer.

The loading capacity of nanocontainers can be enhanced by using both hollow and porous nanostructures. In a specific context, nanocontainer can refer to the nanoshells (with its nano-space), i.e. nanocapsule. Various forms of nanoshells such as metallic, carbonaceous, inorganic and polymeric types have been synthesized. These nanoshells could prevent the direct contact between the active agents and the adjacent local environments. In addition, the multi-walled shells can also be envisaged to engineer the specific and desired functionality.

On theotherhand, in the drug-deliveryapplications, nanocontainer might also be referred to nanocarrier, as a transport module for the active drugs. It is very important to enhance the drug bioavailability, and to protect the drug from chemical or metabolic alterations on their delivering pathways towards the target cells.

\section{Classification}

Nanocontainer can be classified by their nanostructures or their synthetic methods. Regarding the nanostructures, nanocontainer can be divided into 3 main groups including: i) nanoparticles based nanomaterials (three-dimensional nanostructure) [1-4], ii) nanotubes (one dimension) [5-8], and iii) nanolayers based nanomaterials (two-dimensional nanostructure) [9-11]. Similarly, in terms of synthetic materials,

*Corresponding Author: Tuan Anh Nguyen, Institute for Tropical Technology, Vietnam Academy of Science and Technology, Hanoi, Vietnam, Phone: +84-981952783, Email: ntanh@itt.vast.vn nanocontainers consist of organic or inorganic scaffolds in which the encapsulation of active substances has been carried out. In addition, the mixed (hybrid) metal-organic nanocontainers [12], nano-MOFs (metal-organic frameworks) [13, 14] and gold/polymer core/shell [15-17], have also been achieved. The organic nanocontainers include polymeric [18-24], lipid [25-28] and protein nanocapsules [29-30]. A variety of inorganic nanocontainers have been synthesized, such as silica-based nanomaterials [1-3], layered double hydroxides (LDHs) [10-11], ceramic-based [31], carbon-based nanocontainers (nanotubes/nanohorns) [8, 32] and gold-based nanomaterials (nanocages) [33-34].

\section{Methods for Synthesis of Nanocontainer}

\section{Inorganic nanocontainers}

Hollow nanostructures

Organic hollow nanocontainers could be synthesized by using template-assisted methods. In these methods, a thin layer of organic material is coated on the template to form the core-shell nanostructures. This template core is then removed by using the selective etching or by calcination. Based on the type of templates, there are the soft and hard templating methods. The hard templates are made generally by inorganic materials [35] (like anodic aluminum oxide [36], silica [37], carbon [38]), whereas the soft templates can refer to the organic surfactants [39] and long-chain polymers [35] (eg. amphiphilic molecules containing hydrophilic head and hydrophobic chain) [40]. In practical application, for large scale and low cost, self-templating methods have recently been developed, as the direct synthesis without using the external templates. These new self-templating methods included the surface-protected etching [41], the Kirkendall effect [42], and galvanic replacement [43].

\section{Porous nanostructures}

Porous structured nanocontainers are mainly based on mesoporous silica and zirconia. Mesoporous nanosilica could be synthesized by several methods, such as sol-gel method (Stöber process) [44, 45], spray drying [46], or using template of micellar rods [47] with supramolecular assemblies of surfactants [48].

Hollow mesoporous nanostructures are also reported for drug delivery. Hollow mesoporous zirconia could be prepared by using 
silica nanoparticles as template [49]. Whereas, the hollow mesoporous silica [50] could be synthesized from iron silicate, by selective etching of iron oxide.

\section{Organic nanocontainers}

\section{Polymeric nanocontainers}

Smart hollow polymeric nanocontainers can be used effectively for drug delivery applications. They could be prepared by using the layer-by-layer (LbL) deposition of smart (stimuli-responsive) polymeric coatings on sacrificial templates [51].

Polymeric nanocontainers could be prepared by various methods, such as suspension polymerization [52], emulsion polymerization [53], self-assembly [54], core-shell precursors [55], dendrimer [56, 57].

\section{Lipid nanocapsules}

Lipid nanocapsules are reported as new platform for nanomedicine [58] Lipid nanocapsules are the hybrid of polymeric nanocapsules and liposomes. They could be typically prepared by PIT (phase inversion temperature) process using nonionic surfactants, oily and aqueous phases.

\section{Protein nanocapsules}

Protein nanocapsules could be prepared by various emulsification methods, such as single/double emulsions [59, 60], polymerization [61], phase separation/coacervation [62], spray drying/spray congealing $[63,64]$ and ultrasonic emulsification [65].

\section{Loading and Release Processes}

Regarding the loading process, active substances can be loaded into nanocontainers during [66] or after [67-69] the synthesis process. After the synthesis, nanocontainers could be directly loaded with the active agents [67-68] or using the assisted loading transfer process [69]. In some cases, the loading process will be followed by the closing of the pores [70] or by the formation of the nanotube-end stoppers [7172]. For the release process, the active agents could be released from nanocontainers by external or internal stimuli, which referred to the chemical/physical/biochemical changes within or surrounding of the nanocontainer. For instance, various controlled release methodologies of active agents have been reported, such as desorption controlled release [73], pH-controlled release [1, 34, 70], temperature-responsive control [22], ion-exchange control [74, 75], redox-responsive control of release $[76,77]$, light-responsive controlled-release $[78,79]$ and release under mechanical rapture [80, 81].

\section{Applications}

Various kinds of active agents could be embedded inside the nanocontainer, such as drugs, self-healing agents, corrosion inhibitors, catalysts, fertilizers, pesticides, biocides, antioxidants, nutrients, gases.

\section{Agri-food productions}

It was reported that nanocontainers could enhance the efficiency of fertilizers [82] and insect pest control [83, 84]. Bio char-based fertilizers can be applied at low doses and low costs $[85,86]$. Various types of effective nano-fertilizers are also reported, such as cochleate nanotubes based fertilizers [87], nanoporous zeolites [88]. As smart fertilizers, their active ingredients could be released "on demand" (conditional release) [89]. In addition, nanocontainers can be used for delivery of antioxidants/nutrients to foods [90] or for food preservation/ fortification [91].

\section{Anticorrosion}

Various inhibitors have been loaded into nanocontainers, such as benzotriazole [92], mercaptobenzothiazole [68, 93], mercaptobenzimidazole [94], hydroxyquinoline [95], dodecylamine [96], molybdate salts
[97]. Several biocides have been loaded into the nanocontainers, such as zinc pyrithione and copper pyrithione [98], benzalkonium chloride [99], mercaptobenzothiazole and 4,5-Dichloro-2-octyl-4-isothiazolin-3-one (DCOIT) [100], commercial antifouling compounds [101].

\section{Drug delivery, cell imaging and hyperthermia}

In pharmaceutical applications, nanocontainers have advantages over their micro counterparts, such as more efficient drug detoxification, increased specificity of drugs, higher intracellular uptake, better stability, fewer/less side effects and higher biocompatible with tissues, cells, and other biological environments. It was reported that various types of drug could be loaded into nanocontainers, such as anticancer [102], chemotherapeutic drug [103], retroviral drugs (against AIDS) [104], Alzheimer's disease [105], infectious and inflammatory diseases [106], wound healing drug [107], intracellular drug [108], transdermal drug [109], pulmonary drug [110].

In addition, nanocontainers can be also used for cell imaging [111, 112] and hyperthermia $[113,114]$ applications.

\section{Molecular biology}

The compartmentalized biomimetic nanocontainers could be used for artificial cell-like systems [115]. These nano-compartments are typically based on lipid vesicles (liposomes) and synthetic analogs of liposomes (polymersomes) [116]. Their applications include synthetic vesicles [117] and (enzyme) nanoreactors [118].

\section{Gas storage}

Hydrogen could be stored in carbonaceou nanoconatainers (upon compression at low temperature) [119-121] and in metallic nanocontainers (at room temperature) [122,123]. In case of Pd hollow spheres, Pd nanoshells could play the dual catalytic role (dissociation/recombination of hydrogen molecule), that enhanced their storage capacity [122]. Other kinds of gases, like methane [124], argon [125] and oxygen [7], could also be stored in nanotubes based containers.

\section{Environment}

By removing various kinds of organic and inorganic pollutants, carbon nanotubes based adsorbents can be used effectively in wastewater treatment $[126,127]$. In addition, carbon nanotube membranes can be used for water purification [128].

Air remediation under visible light irradiation could be obtained by using $\mathrm{TiO}_{2} / \mathrm{CNTs}$ nanohybrids $[129,130]$.

\section{Smart coatings}

In coating technology, the smart nanocontainers have the ability to release encapsulated active agents via the controlled ways. This makes coatings uniquely well suited for the applications in corrosion protection, self-healing, detection, delivery of bioactive species, fire retardant and antifouling [131]. By the presence of nanocontainers, smart coatings can respond simultaneously either to the changes of coating integrity, or to the variations in the surrounding environment.

The domains of application for smart nanocontainers are expected to be much larger in the future. Researchers now is trying to shed more light on the underlying phenomenal and fundamental mechanisms through which active agents release from nanocontainers, thus provide guidance for their molecular design in the new promising applications.

\section{References}

1. Dai L, Zhang Q, Li J, Shen X, Mu C, et al. (2015) Dendrimerlike Mesoporous Silica Nanoparticles as pH-Responsive Nanocontainers for Targeted Drug Delivery and Bio imaging, ACS Appl. Mater. Interfaces 7: 7357-7372. 
2. JiaJun $\mathrm{Fu}$, Tao Chen, MingDong Wang, NianWang Yang, SuNing Li, et al. (2013) Acid and Alkaline Dual Stimuli-Responsive Mechanized Hollow Mesoporous Silica Nanoparticles as Smart Nanocontainers for Intelligent Anticorrosion Coatings, ACS Nano 7 : 11397-11408.

3. Kaushik Patel, Sarah Angelos, William R. Dichtel, Ali Coskun, et al. (2008) Enzyme-Responsive Snap-Top Covered Silica Nanocontainers, J. Am. Chem. Soc 130: 2382-2383.

4. Avnesh Kumari Sudesh, Kumar Yadav Subhash, C. Yadav (2010) Biodegradable polymeric nanoparticles based drug delivery systems, Colloids and Surfaces B: Bio interfaces 75: 1-18.

5. Dmitry G. Shchukin, S. V. Lamaka, K. A. Yasakau, M. L. Zheludkevich, M. G. S. Ferreira, et al. (2008) Active Anticorrosion Coatings with Halloysite Nanocontainers, J. Phys. Chem. C 112 : 958-964.

6. Abdullayev E, Lvov Y (2010) Clay nanotubes for corrosion inhibitor encapsulation: release control with end stoppers, J. Mater. Chem 20: 6681-6687.

7. Giuseppe Cavallaro, Giuseppe Lazzara, Stefana Milioto, Giovanni Palmisano, Filippo Parisi (2014) Halloysite nanotube with fluorinated lumen: Non-foaming nanocontainer for storage and controlled release of oxygen in aqueous media, Journal of Colloid and Interface Science 417: 66-71.

8. Silke Hampel, Doreen Kunze, Diana Haase, Kai Krämer, Mandy Rauschenbach, et al. (2008), Carbon nanotubes filled with a chemotherapeutic agent: a nanocarrier mediates inhibition of tumor cell growth, Nanomedicine $3: 175-182$.

9. M. L. Zheludkevich, S. K. Poznyak, L.M.Rodrigues, D.Raps, T. Hack et al. (2010) Active protection coatings with layered double hydroxide nanocontainers of corrosion inhibitor, Corrosion Science 52: 602-611.

10. E. Alibakhshi, E. Ghasemi, M. Mahdavian, B. Ramezanzadeh (2017) A comparative study on corrosion inhibitive effect of nitrate and phosphate intercalated $\mathrm{Zn}$-Al- layered double hydroxides (LDHs) nanocontainers incorporated into a hybrid silane layer and their effect on cathodic delamination of epoxy topcoat, Corrosion Science 115: 159-174.

11. Jorge Carneiro, Ana F. Caetano, Alena Kuznetsova, Frederico Maia, Andrei N. Salak, et al. (2015) Polyelectrolyte-modified layered double hydroxide nanocontainers as vehicles for combined inhibitors, RSC Adv 5: 39916-39929.

12. Ping Jin, Scott J. Dalgarno, Jerry L. Atwood (2010).Mixed metal-organic nanocapsules, Coordination Chemistry Reviews 254: $1760-1768$.

13. Sérgio M. F. Vilela , Pablo Salcedo-Abraira, Isabelle Colinet, FabriceSalles, Martijn C. de Koning (2017) Nanometric MIL-125-NH2 Metal-Organic Framework as a Potential Nerve Agent Antidote Carrier, Nanomaterials 7: 321.

14. Witri Wahyu Lestari, Maria Arvinawati, Ronny Martien, Trian Kusumaningsih (2018) Green and facile synthesis of MOF and nano MOF containing zinc(II) and benzen 1,3,5-tri carboxylate and its study in ibuprofen slow-release, Materials Chemistry and Physics 204:141-146.

15. Yavuz MS, Cheng Y, Chen J, Cobley CM, Zhang Q, et al. (2009) Gold nanocages covered by smart polymers for controlled release with near-infrared light, Nat Mater 8: 935-939.

16. Weiyang Li, XinCai, Chulhong Kim, Guorong Sun, Yu Zhang, et al. (2011) Gold Nanocages Covered with Thermally-responsive Polymers for Controlled Release by High-intensity Focused Ultrasound, Nanoscale 3: 1724-1730.

17. Niikura K, Iyo N, Matsuo Y, Mitomo H, Ijiro K. (2013) Sub-100 nm gold nanoparticle vesicles as a drug delivery carrier enabling rapid drug release upon light irradiation, ACS Appl Mater Interfaces 5: 3900-7.

18. Avik Samanta, Matthias Tesch, Ulrike Keller, Jürgen Klingauf, ArmidoStuder, et al. (2015) Fabrication of Hydrophilic Polymer Nanocontainers by Use of Supramolecular Templates, J. Am. Chem. Soc 137 : 1967-1971.

19. Xian Jun Loh, Jesús del Barrio, Pearl Pei Chern Toh, Tung-Chun Lee, Dezhi Jiao, et al. (2012) Triply Triggered Doxorubicin Release From Supramolecular Nanocon- tainers, Biomacromolecules 13: 84-91.

20. Chau Hon Ho, Matthias Thiel, Seref Celik, Erich K. Odermatt, Ingo Berndt, et al. (2012) Conventional and microwave-assisted synthesis of hyperbranched and highly branched polylysine towards amphiphilic core-shell nanocontainers for metal nanoparticles, Polymer 53 : 4623-4630.

21. Atsushi Harada, Kazunori Kataoka, (2006) Supramolecular assemblies of block copolymers in aqueous media as nanocontainers relevant to biological applications Progress in Polymer Science 31: 949-982.

22. Xiangrong Chen, Xiaobin Ding, Zhaohui Zheng, Yuxing Peng (2004) A Self-Assembly Approach to Temperature-Responsive Polymer Nanocontainers, Macromolecular Rapid Communications 25:1575-1578.

23. U. Bazyliska, D. Wawrzyczyk, J. Kulbacka, R. Frckowiak, B. Cichy, et al. (2016) Polymeric nanocapsules with up-converting nanocrystals cargo make ideal fluorescent bioprobes, Scientific Report.

24. T. Chen, J. Fu (2012) An intelligent anticorrosion coating based on $\mathrm{pH}$-responsive supramolecular nanocontainers, Nanotechnology 23: 505.

25. A.A.Attama, C. C. Müller-Goymann (2007) Investigation of surface-modified solid lipid nanocontainers formulated with a heterolipid-templated homolipid, International Journal of Pharmaceutics 334: 179-189.

26. Tarahovsky Y. S. (2010) "Smart" liposomal nanocontainers in biology and medicine, Biochemistry (Mosc) 75:811-824.

27. Puglia C, Offerta A, Carbone C, Bonina F, Pignatello R, Puglisi G. (2015) Lipid nanocarriers (LNC) and their applications in ocular drug delivery, Curr Med Chem 22: 589-602.

28. Nirbhavane .P, Vemuri .N, Kumar .N, Khuller G.K. (2017) Lipid Nanocarrier-Mediated Drug Delivery System to Enhance the Oral Bioavailability of Rifabutin, AAPS Pharm Sci Tech 18: 829-837.

29. K. Heinze, E. Sasaki, N. P. King, D. Baker, D. Hilvert, et al. (2016) Protein Nanocontainers from Nonviral Origin: Testing the Mechanics of Artificial and Natural Protein Cages by AFM, J. Phys. Chem. B 120: 5945-5952.

30. Piradashvili K, Fichter M, Mohr K, Gehring S, Wurm FR et al. (2015) Biodegradable protein nanocontainers, Biomacromolecules 16: 815-821.

31. I.A.Kartsonakis, A. C. Balaskas, E. P. Koumoulos, C.A. Charitidis, G.C. Kordas (2012) Incorporation of ceramic nanocontainers into epoxy coatings for the corrosion protection of hot dip galvanized steel, Corrosion Science 57: 30-41.

32. Kumiko Ajima, Masako Yudasaka, Tatsuya Murakami, Alan Maigné, Kiyotaka Shiba, Sumio Iijima (2005) Carbon Nanohorns as Anticancer Drug Carriers, Mol. Pharm 2 : 475-480.

33. Bo Pang, Xuan Yang, Younan Xia (2016) Putting gold nanocages to work for optical imaging, controlled release and cancer theranostics, Nanomedicine (Lond) 11: 1715-1728.

34. Peng Shi, Konggang $\mathrm{Qu}$, Jiasi Wang, Meng Li, Jinsong Ren, et al. (2012) pH-responsive NIR enhanced drug release from gold nanocages possesses high potency against cancer cells, Chem. Commun 48: 7640-7642.

35. Qiao Zhang, Wenshou Wang, James Goebl, Yadong Yin (2009) Self-templated synthesis of hollow nanostructures, Nano Today 4:494-507.

36. Y. Wang, J.Y. Lee, H.C. Zeng (2005) Polycrystalline SnO2 Nanotubes Prepared via Infiltration Casting of Nanocrystallites and Their Electrochemical Application, Chem. Mater 17: 3899-3903.

37. S. Ding, J.S. Chen, G. Qi, X. Duan, Z. Wang, et al. (2011) Formation of SnO2 Hollow Nanospheres inside Mesoporous Silica Nanoreactors, J. Am. Chem. Soc. 133: 21-23.

38. J.H. Bang, K.S. Suslick (2007) Sonochemical Synthesis of Nanosized Hollow Hematite, J. Am. Chem. Soc 129: 2242-2243.

39. H. Xu, W. Wang (2007) Template Synthesis of Multishelled $\mathrm{Cu} 2 \mathrm{O}$ Hollow Spheres with a Single-Crystalline Shell Wall, Angew. Chem 46:1489-1492.

40. J. H. Fendler (1987) Atomic and molecular clusters in membrane mimetic chemistry, Chem. Rev 87: 877-899.

41. Q. Zhang, T. Zhang, J. Ge, Y. Yin (2008) Permeable Silica Shell through Surface-Protected Etching, Nano Lett 8:2867-2871. 
42. Y. Yin, R.M. Rioux, C.K. Erdonmez, S. Hughes, G.A. Somorjai, et al. (2004) Formation of hollow nanocrystals through the nanoscale Kirkendall effect, Science 304:711-714.

43. H.M. Chen, R.S. Liu, M.Y. Lo, S.C. Chang, L.D. Tsai, et al. (2008) Hollow Platinum Spheres with Nano-Channels: Synthesis and Enhanced Catalysis for Oxygen Reduction, J. Phys. Chem. C 112: 7522-7526.

44. Nandiyanto, Asep Bayu, Dani Kim, Soon-Gil Iskandar, Ferry Okuyama, et al. (2009). Synthesis of Silica Nanoparticles with Nanometer-Size Controllable Mesopores and Outer Diameters, Microporous and Mesoporous Materials 120: 447-453.

45. Adrian Szewczyk, Magdalena Prokopowicz (2018) Amino-modified mesoporous silica SBA-15 as bifunctional drug delivery system for cefazolin: Release profile and mineralization potential, Materials Letters 227:136-140.

46. Nandiyanto, Iskandar. F, Okuyama. K (2008) Nano-sized Polymer Particle-Facilitated Preparation of Mesoporous Silica Particles Using a Spray Method, Chemistry Letters 37 : 1040-1041.

47. Trewyn, Brian G, Nieweg, Jennifer A, Zhao, Yannan Lin, et al. (2007) Biocompatible mesoporous silica nanoparticles with different morphologies for animal cell membrane penetration, Chemical Engineering Journal 137 :23-29.

48. Yixian Zhou, Guilan Quan, Qiaoli Wu, Xiaoxu Zhang, Boyi Niu et al. (2018) Mesoporous silica nanoparticles for drug and gene delivery, Acta Pharmaceutica Sinica B 8:165-177.

49. Arunchandran Chenan, S. Ramya, R.P. George, U. Kamachi Mudali (2014) Hollow mesoporous zirconia nanocontainers for storing and controlled releasing of corrosion inhibitors, Ceramics International 40:10457-10463.

50. Chandan Adhikaria, Anurag Mishrab, Debasis Nayakb, Anjan Chakrabortya (2018) Drug delivery system composed of mesoporous silica and hollowmesoporous silica nanospheres for chemotherapeutic drug delivery, Journal of Drug Delivery Science and Technology 45: 303-314.

51. Guo-Dong Fu, Guo Liang Li, K.G. Neoh, E.T. Kang (2011) Hollow polymeric nanostructures-Synthesis, morphology and Function, Progress in Polymer Science 36: 127-167.

52. M. Okubo, Y. Konishi, H. Minami (1998) Production of hollow polymer particles by suspension polymerization, Colloid Polym. Sci 276: 638-642.

53. O. Emmerich, N. Hugenberg, M. Schmidt, S.S. Sheiko, F. Baumann, et al. (1999) Molecular Boxes Based on Hollow Organosilicon Micronetworks, Adv. Mater 11:1299-1303.

54. Annette Rösler, Guido W.M. Vandermeulen, Harm-Anton Klok (2012) Advanced drug delivery devices via self-assembly of amphiphilic block copolymers, Advanced Drug Delivery Reviews 64: 270-279.

55. Poux S, Meier W. (2005) Synthesis and characterization of new polymer nanocontainers. Macromol Symp 222:157-162.

56. J.F.G.A. Jansen, D.A.F.J. Van Boxtel, E.M.M. de Brabander-van den Berg, E.W. Meijer (1995), The Dendritic Box: Shape-Selective Liberation of Encapsulated Guests, J. Am.Chem. Soc 117: 4417-4418.

57. Dharma Rao Vutukuri, Subhadeep Basu, S. Thayumanavan (2004) Dendrimers with Both Polar and Apolar Nanocontainer Characteristics, J. Am. Chem. Soc 126: 15636-15637.

58. N.T. Huynh, C. Passirani, P. Saulnier, J.P. Benoit (2009) Lipid nanocapsules: A new platform for nanomedicine, International Journal of Pharmaceutics 379:201-209.

59. P. Erni, P. Fischer and E. J. Windhab (2005) Deformation of single emulsion drops covered with a viscoelastic adsorbed protein layer in simple shear flow.

60. Y.-Y. Yang, T.-S.Chung, X.-L.Bai and W.-K. Chan (2000) Effect of preparation conditions on morphology and release profiles of biodegradable polymeric microspheres containing protein fabricated by double-emulsion method, Chem. Eng. Sci 55: 2223-2236.

61. X. Huang and W. J. Brittain (2001) Synthesis and Characterization of PMMA Nanocomposites by Suspension and Emulsion Polymerization, Macromolecules 34: 3255-3260.

62. P. J. Dowding, R. Atkin, B. Vincent, P. Bouillot (2005) Oil Core/Polymer Shell Microcapsules by Internal Phase Sep- aration from Emulsion Droplets. II: Controlling the Release Profile of Active Molecules, Langmuir 21: 5278-5284.

63. A.Maschke, C. Becker, D. Eyrich, J. Kiermaier, T. Blunk (2007) A.Go"pferich, Development of a spray congealing process for the preparation of insulin-loaded lipid microparticles and characterization thereof, Eur. J. Pharm. Bio pharm 65:175-187.

64. G. Jiang, B. C. Thanoo, P. P. DeLuca (2002) Effect of osmotic pressure in the solvent extraction phase on BSA release profile from PLGA microspheres, Pharm. Dev Technol 7: 391-399.

65. R.Silva,H.Ferreira,N.G.Azoia,U.Shimanovich,G.Freddi,etal.(2012) Insights on the Mechanism of Formation of Protein Microspheres in a Biphasic System, Mol. Pharmaceutics 9:3079-3088.

66. U. Bazylińska, D. Wawrzyńczyk, J. Kulbacka, R. Frąckowiak, B. Cichy, et al.(2016) Polymeric nanocapsules with up-converting nanocrystals cargo make ideal fluorescent bioprobes.

67. S. Manasa, A. Jyothirmayi, T. Siva, S. Sathiyanarayanan, K. V. Gobi, R. Subasri (2017) Effect of inhibitor loading into nanocontainer additives of self-healing corrosion protection coatings on aluminum alloy A356.0, Journal of Alloys and Compounds 5: 969-977.

68. Arunchandran Chenan, S. Ramya, R.P. George, U. Kamachi Mudali (2014) 2-Mercaptobenzothiazole-Loaded Hollow Mesoporous Silica-Based Hybrid Coatings for Corrosion Protection of Modified 9Cr-1Mo Ferritic Steel, Corrosion, 2014; 70:496-511.

69. Alexandra Graff, Marc Sauer, Patrick Van Gelder, Wolfgang Meier (2002) Virus-assisted loading of polymer nanocontainer 99: 5064-5068.

70. Hong CY, Li X, Pan CY (2009) Fabrication of smart nanocontainers with a mesoporous core and a $\mathrm{pH}$-responsive shell for controlled uptake and release. J Mater Chem 19:55-60.

71. Dzamukova MR, Naumenko EA, Lvov YM, Fakhrullin RF (2015) Enzyme-activated intracellular drug delivery with tubule clay nanoformulation, Sci Reports 5:10560-10566.

72. Wenbo Wei, Renata Minullina, Elshad Abdullayev, Rawil Fakhrullin, David Mills, et al. (2014) Enhanced efficiency of antiseptics with sustained release from clay nanotubes, RSC Adv 4:488-495.

73. M.L. Zheludkevich, R. Serra, M.F. Montemor, K.A. Yasakau, I.M.M. Salvado, et al. (2005) Nanostructured sol-gel coatings doped with cerium nitrate as pre-treatments for AA2024-T3 Corrosion protection performance, ElectrochimicaActa, $51: 208-217$.

74. K. Poznyak, J. Tedim, L.M. Rodrigues, A.N. Salak, M.L. Zheludkevich, et al. (2009) Novel Inorganic Host Layered Double Hydroxides Intercalated with Guest Organic Inhibitors for Anticorrosion Applications, ACS Applied Materials \& Interfaces $1: 2353-2362$.

75. J. Tedim, S.K. Poznyak, A. Kuznetsova, D. Raps, T. Hack, et al. (2010), Enhancement of Active Corrosion Protection via Combination of Inhibitor-Loaded Nanocontainers, ACS Applied Materials \& Interfaces $2: 1528-1535$.

76. Roland H. Staff, Markus Gallei, Markus Mazurowski, Matthias Rehahn, Rüdiger Berger et al. (2012) Patchy Nanocapsules of Poly(vinylferrocene)-Based Block Copolymers for Redox-Responsive Release, ACS Nano 6 :9042-9049

77. Xuejuan Wan, Di Wang, Shiyong Liu (2010) Fluorescent pH-Sensing Organic/Inorganic Hybrid Mesoporous Silica Nanoparticles with Tunable Redox-Responsive Release Capability, Langmuir 26 : 15574-15579.

78. Marturano.V, Cerruti. P, Carfagna, Giamberini.M, Tylkowski.B (2015) Ambrogi, V. Photo-responsive polymer nanocapsules, Polymer 70: 222-230.

79. Eva-Maria Rosenbauer, Manfred Wagner, Anna Musyanovych, Katharina Landfester (2010) Controlled Release from Polyurethane Nanocapsules via $\mathrm{pH}-$, UV-Light- or Temperature-Induced Stimuli, Macromolecules 43 : 5083-5093

80. Cesia Ávila-Gonzalez, Rodolfo Cruz-Silva, CarminaMenchaca, Selene Sepulveda-Guzman, Jorge Uruchurtu (2011) Use of Silica Tubes as Nanocontainers for Corrosion Inhibitor Storage, Journal of Nanotechnology.

81. S. Amiri, A. Rahimi (2016) Anticorrosion behavior of cyclodextrins/inhibitor nanocapsule-based self-healing coatings, Journal of Coatings Technology and Research 13: 1095. 
82. Manikandan A, Subramanian KS (2014).Fabrication and characterisation of nanoporous zeolite based $\mathrm{N}$ fertilizer. Afr J Agric Res 9: 276-284.

83. Vidyalakshmi R, Bhakyaraj R, Subhasree RS (2009) Encapsulation "the future of probiotics" - A review, Adv Biol Res 3:96-103.

84. Yang FL, Li XG, Zhu F, Lei CL (2009) Structural characterization of nano $\neg$ particles loaded with garlic essential oil and their insecticidal activity against Tribolium castaneum (Herbst) (Coleoptera: Tenebrionidae). J Agric Food Chem 57:10156-10162.

85. Joseph S, van Zwieten L, Chia CH (2013) 'Designing' of biochar for specific applications to soils; a technology in its infancy. In: Biochar and Soil Biota. Ladygina N, Rineau F (Eds). CRC Press, Boca Raton, FL, USA.

86. S Joseph, ER Graber, C Chia, P Munroe, S Donne e al. (2013) Shifting paradigms: development of high-efficiency biochar fertilizers based on nano-structures and soluble components, Carbon Management 4:323-343.

87. De Rosa MR, Monreal C, Schnitzer M, Walsh R, Sultan Y (2010) Nanotechnology in fertilizers. Nat. Nanotechnol 5: 91.

88. Li Z. 2003. Use of surfactant-modified zeolite as fertilizer carriers to control nitrate release. Microporous and Mesoporous Materials 61:181-188.

89. M. R. Naderi, A. Danesh-Shahraki (2013) Nanofertilizers and their roles in sustainable agriculture, Intl J Agri Crop Sci 5: 22292232.

90. Chunjing Guo, JungangYin, Daquan Chen(2018) Co-encapsulation of curcumin and resveratrol into novel nutraceutical hyalurosomes nano-food delivery system based on oligo-hyaluronic acid-curcumin polymer, Carbohydrate Polymers 1 : 1033-1037.

91. Moises Job Galindo-Pérez, David Quintanar-Guerrero, María de los Ángeles Cornejo-Villegas, María de la Luz Zambrano-Zaragoz (2018) Optimization of the emulsification -diffusion method using ultrasound to prepare nanocapsules of different foodcore oils, LWT - Food Science and Technology 87: 333-341.

92. Elshad Abdullayev, Ronald Price, Dmitry Shchukin, Yuri Lvov(2009) Halloysite Tubes as Nanocontainers for Anticorrosion Coating with Benzotriazole, ACS Appl. Mater Interfaces 1 : 1437-1443.

93. D, Yu, J. Wang, W. Hu, R. Guo (2017) Preparation and controlled release behavior of halloysite/2-mercaptobenzothiazole nanocomposite with calcined halloysite as nanocontainer, Materials \& Design 129: 103-110.

94. Elshad Abdullayev, Vagif Abbasov, Asel Tursunbayeva, Vasiliy Portnov, Hikmat Ibrahimov et al. (20130 Self-Healing Coatings Based on Halloysite Clay Polymer Composites for Protection of Copper Alloys, ACS Appl. Mater. Interfaces 5:4464-4471.

95. Ioannis Kartsonakis, Ioannis Daniilidis, George Kordas (2008) Encapsulation of the corrosion inhibitor 8-hydroxyquinoline into ceria nanocontainers, Journal of Sol-Gel Science and Technology 48: 24-31.

96. J. M. Falcón, L.M. Otubo, I.V.Aoki (2016) Highly ordered mesoporous silica loaded with dodecylamine for smart anticorrosion coatings, Surface and Coatings Technology 303: 319-329.

97. A.Keyvani, M. Yeganeh, H.Rezaeyan(2017) Application of mesoporous silica nanocontainers as an intelligent host of molybdate corrosion inhibitor embedded in the epoxy coated steel, Progress in Natural Science: Materials International 27: 261-267.

98. Eldad Gutner-Hoch, Roberto Martins, Tania Oliveira, Frederico Maia, Amadeu M. V. et al. (2018) Antimacrofouling Efficacy of Innovative Inorganic Nanomaterials Loaded with Booster Biocides, J. Mar. Sci. Eng 6: 6.

99. Zhaoliang Zheng, Xing Huang, Matthias Schenderlein, Dimitriya Borisova, Rong Cao (2013) Dmitry Shchukin, Self-Healing and Antifouling Multifunctional Coatings Based on $\mathrm{pH}$ and Sulfide Ion Sensitive Nanocontainers, Advanced Functional Materials, Volume 23: 3307-3314.

100. F. Maia, A.P. Silva, S. Fernandes, A. Cunha, A. Almeida et al. (2015) Incorporation of biocides in nanocapsules for protective coatings used in maritime applications, Chemical Engineering Journal 270:150-157.

101. Aristotelis Kamtsikakis, Eleni Kavetsou, Konstantina Chronaki, Evangelia Kiosidou, Evangelia Pavlatou et al. (2017) En- capsulation of Antifouling Organic Biocides in Poly(lactic acid) Nanoparticles, Bioengineering (Basel) 4:81.

102. Julien Nicolas, Patrick Couvreur (2017) Polymer nanoparticles for the delivery of anticancer drug, Medecine Sciences 33:11-17.

103. Lin Kang, Zhonggao Gao, Wei Huang, Mingji Jin, QimingWang (2015) Nanocarrier-mediated co-delivery of chemotherapeutic drugs and gene agents for cancer treatment, Acta Pharmaceutica Sinica B 5: 169-175.

104. Patricia Horcajada, Christian Serre, Gérard Férey, Patrick Couvreur ,Ruxandra Gref, (2010) Hybrid nanocarriers for controlled delivery of antitumour and retroviral drugs delivery, Medecine Sciences 26:761-767.

105. Sihem Doggui, Lé Dao, Charles Ramassamy (2012) Potential of drug-loaded nanoparticles for Alzheimer's disease: diagnosis, prevention and treatment, Therapeutic Delivery 3: 9.

106. Ufuoma Ikoba, Haisheng Peng, Haichun Li, Cathy Miller, Chenxu Yu (2015) Nanocarriers in therapy of infectious and inflammatory diseases, Nanoscale 7: 4291-4305

107. Sweta Garg, Ashish Garg, Ajay Shukla, Suresh Kumar Dev, Manish Kumar(2018) A review on Nano-therapeutic drug delivery carriers for effective wound treatment strategies, Asian Journal of Pharmacy and Pharmacology 4: 90-10.

108. Vladimir P. Torchilin( 2008) Cell penetrating peptidemodified pharmaceutical nanocarriers for intracellular drug and gene delivery, Peptide Science 90: 604-610.

109. José Juan Escobar-Chávez, Isabel Marlen Rodríguez-Cruz,Clara Luisa Domínguez-Delgado, Roberto Díaz-Torres,Alma Luisa Revilla-Vázquez et al. (2012) Nanocarrier Systems for Transdermal Drug Delivery, In " Recent Advances in Novel Drug Carrier Systems”, Eds. Ali Demir Sezer, IntechOpen 978-953.

110. Malgorzata Smola, Thierry Vandamme, Adam Sokolowski (2008) Nanocarriers as pulmonary drug delivery systems to treat and to diagnose respiratory and non respiratory diseases, Int J Nanomedicine. 3:1-19.

111. T. Zhou, B. Wu, D. Xing (2012) Bio-modified $\mathrm{Fe} 3 \mathrm{O} 4$ core/ $\mathrm{Au}$ shell nanoparticles for targeting and multimodal imaging of cancer cells, J. Mater 22: 470-477.

112. Yu Chen, Hangrong Chen, Deping Zeng, Yunbo Tian, Feng Chen et al. (2010) Core/Shell Structured Hollow Mesoporous Nanocapsules: A Potential Platform for Simultaneous Cell Imaging and Anticancer Drug Delivery, ACS Nano 4: 6001-6013.

113. Mohammad F, Balaji G, Weber A, Uppu R ,Kumar C (2010) Influence of gold nanoshell onhyperthermia of superparamagnetic iron oxide nanoparticles. Phys. Chem. C 114:19194-19201.

114. Das R, Rinaldi-Montes N, Alonso J, Amghouz Z, Garaio E et al. (2016) Boosted Hyperthermia Therapy by Combined $\mathrm{AC}$ Magnetic and Photothermal Exposures in $\mathrm{Ag} / \mathrm{Fe} 3 \mathrm{O} 4$ Nanoflowers, ACS Appl. Mater. Interfaces 8:25162-25169.

115. TatianaTrantidou,MarkFriddin, YuvalElani,NicholasJ.Brooks, Robert V.Law, et al. (2007) Engineering Compartmentalized Biomimetic Micro- and Nanocontainers ACS Nano 11:6549-6565.

116. V. Malinova a, M. Nallani c, W.P. Meier a, E.K. Sinner (2012) Synthetic biology, inspired by synthetic chemistry, FEBS Letters 586:2146-2156.

117. LeaMessager,JonathanR.Burns,Jungyeon Kim,DenisCecchin,James Hindley et al (2016) Biomimetic Hybrid Nanocontainers with Selective Permeability, Angew Chem Int Ed Engl 55: 11106-11109.

118. Pavel Broz, Sergey Driamov, Joerg Ziegler, Nadav Ben-Haim,Stephan Marsch, Wolfgang Meier et al. (2006) Toward Intelligent Nanosize Bioreactors: A pH-Switchable, Channel-Equipped, Functional Polymer Nanocontainer, Nano Letters 6: 2349-2353.

119. A.V. Vakhrushev, M. V. Suetin (2009) Carbon nanocontainers for gas storage, Nanotechnol Russia 4: 806-815.

120. Y. X. Ren, T. Y. Ng, K. M. Liew( 2005) State of Hydrogen Molecules Confined in C60 Fullerene and Carbon Nanocapsule Structures, Carbon 44 :397-406.

121. X. Ye, X. Gu, X. G. Gong, T. K. M. Shing et al (2007) Z. F. Liu, A Nanocontainer for the Storage of Hydrogen, Carbon 45: 315-320.

122. Suboohi Shervani, Puspal Mukherjee, Anshul Gupta, Gargi Mishra et al. (2017) Multi-mode Hydrogen Storage in Nanocontainers, International Journal of Hydrogen Energy 42:24256. 
123. Felipe J. Valencia, Rafael I. González, Diego Tramontina, José Rogan, Juan Alejandro Valdiviaet al. (2016) Hydrogen Storage in Palladium Hollow Nanoparticles, J. Phys. Chem. C 120 : 23836-23841.

124. MV Suyetin, AV Vakhrushev (2009) Nanocapsule for Safe and Effective Methane Storage, Nanoscale Res Lett 4: 1267-1270.

125. T. Oku, M. Kuno (2003) Synthesis, Argon/Hydrogen Storage, and Magnetic Properties of Boron Nitride Nanotubes and Nanocapsules, Diamond Relat. Mater $12: 840-845$.

126. Venkata K.K.Upadhyayula, Shuguang Deng, Martha C.Mitchell, Geoffrey B.Smith, (2009) Application of carbon nanotube technology for removal of contaminants in drinking water: A review, Science of The Total Environment 408: 1-13.

127. Maryam Ahmadzadeh Tofighy, Toraj Mohammadi (2011) Adsorption of divalent heavy metal ions from water using carbon nanotube sheets, Journal of Hazardous Materials, 185: 140-147.

128. Rasel Dasa, Md. EaqubAli, Sharifah Bee, Abd Ha- mid, Seeram Ramakrishna et al (2014) Carbon nanotube membranes for water purification: A bright future in water desalination, Desalination, Volume 336: 97-109.

129. M. Wongaree, S. Chiarakorn, S. Chuangchote, T. Sagawa (2016) Photocatalytic performance of electrospun CNT/ $\mathrm{TiO} 2$ nanofibers in a simulated air purifier under visible light irradiation Environ. Sci. Pollut. Res 23 : 21395-21406

130. E.Soroodan Miandoab ,Sh. Fatemi (2015) Upgrading $\mathrm{TiO} 2$ Photoactivity under Visible Light by Synthesis of MWCNT/ TiO2 Nanocomposite, Int. J. Nanosci. Nanotechnol 11:1-12.

131. Sarah B. Ulaeto, Jerin K. Pancrecious, T.P.D. Rajan , B.C. Pai (2018) Smart Coatings, in "Noble metal-metal oxide hybrid nanoparticles: Fundamentals and applications". Satyabrata Mohapatra Tuan Anh Nguyen Phuong Nguyen-Tri (Eds.), Elsevier, Woodhead Publishing, USA. 